\title{
The influence of the business environment on the growth of informal businesses in Uganda
}

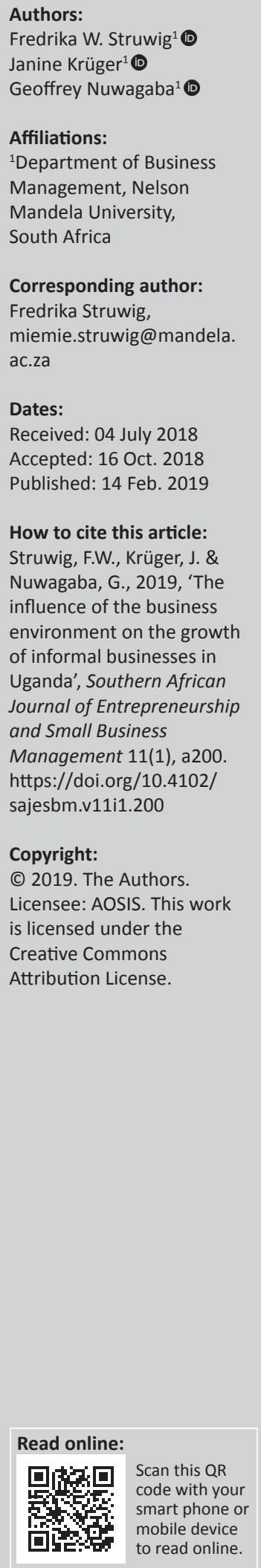

Background: Informal businesses are important drivers of economic growth, especially in developing countries. These informal businesses often do not survive their first year of existence, with anecdotal evidence citing various challenges from the business environment.

Aim: This study explored the influence of business environmental challenges on the growth of informal businesses in Uganda.

Setting: There are various challenges from the internal and external environment that impede the growth and survival of informal businesses in Uganda. From the internal business perspective, informal businesses have poor business processes and do not have proper business strategies on which to focus their business growth strategies. From the external environment perspective, informal businesses do not understand their suppliers adequately. In addition, there is a lack of research on the relationships between internal and external business environments and the growth of informal businesses.

Method: Primary data were collected from 383 informal businesses using a self-administered questionnaire. The data were analysed using descriptive statistics in SPSS 21.0 (Statistical Package for the Social Sciences), while the relationship between the variables was determined using Pearson's product moment correlation coefficient and tested using regression analysis and analysis of variance (ANOVA).

Results: The results showed that there was a significant positive directional relationship between the internal environment and the growth of informal businesses. However, there was a negative significant directional relationship between the external environment and the growth of informal businesses.

Conclusions: Informal businesses should pay more attention to the internal environment and appropriate strategies should be developed and implemented to ensure their growth.

\section{Introduction}

Informal businesses are regarded as important drivers of economic growth, especially in developing countries. This is evident when one considers that the informal sector in Uganda contributes $49 \%$ of the gross domestic product (GDP) of the country (Kasemiire 2017:2). These informal businesses contribute to the production of goods and services, provide employment and are regarded as the livelihood for the poor (Deen-Swarray, Ndiwalana \& Stork 2013:1). Despite their importance, anecdotal evidence shows that informal businesses in Uganda do not exist longer than a year citing various challenges from the internal and external environment that impede their survival and growth. From the internal business perspective, informal businesses are managed by owners who lack knowledge and skills in areas such as cash planning, cash forecasting, short-term investment of surplus cash, financial controls and reporting as well as debtor management. They also have poor business processes, poor-quality products and services as well as not having proper business strategies to keep these informal businesses focused on growth objectives. From the external environment perspective, informal businesses do not understand their suppliers adequately. They often regard their suppliers as unreliable, they cannot secure supplies on credit and because of their mobile nature, they do not have loyal customers, while their customer base often declines (Uganda Bureau of Statistics [UBOS] 2012). In addition, informal businesses face strong competition because most of the informal businesses sell similar or related products. Another challenge the informal businesses face includes the payment of presumptive taxes that are normally higher than normal business tax (Kasemiire 2017:2). A combination of these challenges anecdotally impedes the growth of these businesses in terms of sales growth, profitability, growth in employment and length of business existence (Uganda Investment Authority 2012). 
Despite the situation, there is a lack of research on the relationships between the business environments (internal and external) and growth of informal businesses, and this situation requires urgent intervention. The investigation of the relationships between these variables will assist in understanding what needs to be performed to ensure the growth of informal businesses. Thus, the aim of this article is to investigate the relationships between the business environments and the growth of informal businesses in Uganda.

\section{Definition of informal businesses and previous research on the growth of informal businesses}

There is no universally accepted definition for informal businesses, but there is an agreement that informal businesses have certain characteristics that differ from those of formal businesses. Informal businesses are small, unregistered businesses operating as street vendors and in-home businesses established on residential sites (Ligthelm 2013:59). Furthermore, informal businesses are described as businesses that correspond to sole traders (own-account workers) and those in small or micro-enterprises (Henley, Arabsheibani \& Carneiro 2006:4). Van Broembsen (2010:260) defines informal businesses as unregistered and having unregulated economic activities that contribute to the GDP. These businesses include casual and contract workers, domestic workers and farm workers, while Barbour and Llanes (2013:22) define informal businesses as businesses involved in the production and distribution of legal goods and services in which there is noncompliance with regulations in areas such as tax, conditions of employment and the claiming of benefits. For the purposes of this article, informal businesses include small, unregistered businesses whose trading location is mostly mobile, and which often evade taxes.

In Uganda, informal businesses seek to meet household needs by supplementing the family income by means of formal employment. In many cases, informal businesses exist as the only option to earn a livelihood for those who have little or no education to engage in gainful opportunities such as waged work (Bukaliya \& Aleck 2012:58). This category of business is generally, but not exclusively, home-based and its business operations are limited because of the small capital base with which they start up and the resultant small profits base to re-invest in the businesses (Ishengoma \& Kappel 2011:352).

Typically, these informal businesses do not have access to fixed premises, accessible roads and utilities. It is reported that the lack of management ability among the owners of the informal businesses is compounded by the lack of collateral to secure loans from financial institutions. When informal businesses attempt to access credit that would enhance their cash positions, some major factors impede their growth, which include the low level of professionalism, poor linkages with large businesses, poor records and account keeping as well as limited knowledge of business opportunities (Kasemiire 2017; UNCTAD 2007). These businesses tend to use simple technology in production, which often negatively impacts on the quality of their products. In addition, many of the informal businesses face limited access to markets and strong competition from other businesses (Ishengoma \& Kappel 2011:352).

Informal businesses play various but vital roles ranging from providing employment to the family members and relatives (Deen-Swarray et al. 2013:1; Delbiso 2013:1) to providing disposable income to the owners and the workforce (Llanes \& Barbour 2007:12). In addition, although not registered by official tax bodies, they contribute to the GDP especially through consumption (Tshuma \& Jari 2013:250). Despite the significance of informal businesses, literature shows that the majority of informal businesses do not grow and survive for long in business (Uganda National Household Survey 2010:143).

Sookram and Watson (2008:1531) investigated the socioeconomic, demographic and attitudinal characteristics of proprietors of informal businesses in emerging economies and their perceptions of the risk of detection by tax authorities. The results of the study suggested that informal businesses decided to participate in the informal sector when, among other factors, they believed that the risk of detection by the tax authorities was low and that government regulations were burdensome. These findings suggested that informal businesses decided to stay as small and informal businesses to avoid tax and other government regulations and therefore deliberately refused to expand and grow in order to avoid identification by the authorities. These findings are supported by a study conducted by Rosemary (2016:410) among female entrepreneurs in Kenya, which also found that the legal and regulating environments hindered the growth potential of informal businesses.

Ademola and Anyankora (2012:218) examined the challenges of improving the conditions of informal businesses in Lagos Island, Nigeria. The study's objectives included identifying informal business activities in the study area, examining the socio-economic characteristics of people involved in the activities, examining the conditions in which they operated, identifying the involvement factors in the informal sector activities in Lagos Island and assessing the problems of managing the sector activities in the study area. Ademola and Anyankora (2012:225) established that informal businesses maintained operations on a small-scale because of a lack of skills for expansion as the majority of the businesses had no specialised education and training to grow their businesses. The results therefore suggested that the lack of specialised business skills, which was highly attributable to low education levels and training, constituted some of the factors affecting the growth of informal businesses.

The Western Cape Provincial Economic Review and Outlook (2007:163) examined the growth of formal small, medium 
and micro-enterprises with a specific focus on informal businesses and growth in employment as one of the measures of growth. The findings showed that while the formal sector appeared to be growing, the informal businesses did not appear to be generating new employment. Informal business employment growth appeared to be stagnant at best, preventing the sector from making a greater contribution to the provincial economy. Furthermore, a study conducted in Kenya supports the notion that the income derived from the informal businesses was used to supplement the family income; therefore, no or little funds were available for expansion or growth purposes (Rosemary 2016:410).

Adhikari (2012:1) examined income generation in the informal sector with specific focus on street vending. It was established that informal businesses required less investment and the income from that investment was satisfactory to at least sustain a family in the city. The study further established that the income and profit from business activities were too low to promote business growth (Adhikari 2012:13). These findings supported the findings by the Western Cape Provincial Economic Review and Outlook (2007:163), which established that informal businesses were driven by survival. The findings suggested that the growth of informal businesses was partly influenced by low-income levels and lack of profitability. In a study by Donner (2007:19), it was established that the majority of the informal businesses did not adopt Information and Communication Technology (ICT) in growing their businesses. Most of the small and informal businesses focused on the customers in the neighbourhoods and not on the new customers even when there was an opportunity using ICT. These findings suggest that informal businesses may remain stagnated in their growth because of the lack of adoption of new technology such as ICT. Ogbokor and Ngeendepi (2012:16) concurred with Donner (2007:19) that informal businesses did not embrace new technological changes to boost their business growth.

Mwobobia (2012:114) noted that informal businesses in Kenya faced a high probability of failure because of their small size. Furthermore, because of their small size, a simple management mistake was likely to lead to closure of a small business; hence, there was no opportunity to learn from its past mistakes. Mwobobia (2012:114) further noted that the lack of planning, improper financing and poor management had been posited as the main causes of failure of small informal businesses. Ogbokor and Ngeendepi (2012:16) investigated challenges facing small businesses where the majority were informal businesses. Ogbokor and Ngeendepi (2012:16) established that informal businesses did not have a clear marketing plan and they did not conduct market research. This often led the informal businesses to underinvest in activities and services that could potentially enhance their productivity and growth.

Van Broembsen (2010:26) points out that one of the major factors influencing informal business growth is business strategy. In addition, it was noted by both Van Broembsen
(2010:26) as well as the Western Cape Provincial Economic Review and Outlook (2007:163) that informal businesses had survivalist strategies that had no potential for growing the informal businesses into sustainable and viable businesses. The results of Alemayehu and Van Vuuren's (2017:262) study highlighted that resource munificence and environment munificence had an impact on business strategies available for business growth. Van Broembsen (2010:261) further identified that wage and working conditions in emerging informal businesses were uniformly poor both for owners and their employees. This questioned the sustainability and quality of the employment generated by informal businesses. Keter (2012:873) found that owners of informal businesses did not have adequate skills to pursue business growth. Rosemary (2016:410) also concurred that the lack of skills, training and education hampered informal business growth. Keter (2012:873) cited that owners may, for instance, incur costs such as bribes to licensing officials, loss of goods because of confiscation and loss of valuable time because of frequent closures, all of which impacted on business growth.

Mbaye and Gueye (2018:25-51) showed that poor business environments affect both formal and informal businesses. A study by Meyer, Meyer and Molefe (2016:127-128) found that many external environmental factors, such as lack of service delivery, labour legislation and crime, influenced the growth of informal businesses. Furthermore, the results highlighted that the lack of marketing, financial and management skills hampered business growth. De Castro, Khavul and Bruton (2014:75-94) conducted a qualitative study that showed that when making decisions about informality, entrepreneurs in emerging economies purposefully chose to remain informal.

\section{Theoretical framework used in this study}

In this study, the focus is on the relationships between the business environments and the growth of informal businesses. The growth of informal business is the dependent variable and the internal and external environments are the independent variables.

\section{Dependent variable: Growth of informal businesses}

One of the measures of the growth of informal businesses is their contribution to the labour market (Alderslade, Talmage \& Freeman 2006:9; Henley et al. 2006:2). Authors such as Alderslade et al. (2006:9) and Sparks and Barnett (2010:1) highlighted that the number of employees engaged in informal businesses was one of the baselines used to measure the growth of informal businesses and further noted that informal businesses with a large number of employees were considered to be at a higher level of growth than businesses with fewer employees. They did not, however, specify the exact number of employees who qualify an informal business as a growing one. The 2017 International Monetary Fund (IMF) report highlighted that the informal sector employed 
between $30 \%$ and $90 \%$ of labour in sub-Saharan Africa. With regard to the informal sector in Uganda, research shows that $27 \%$ of the informal sector is in agriculture, $24 \%$ in trade and services and $1 \%$ in mining and quarrying, respectively (Kasemiire 2017:3).

Ligthelm (2013:59) identified the role of profitability and expansion as measures of informal business growth. Onwe (2013:62) asserted that the majority of informal businesses were not growing because of the lack of sales revenue and profitability. Onwe (2013:62) as well as Bukaliya and Aleck (2012:63) highlighted that some informal businesses had prospects to pursue growth through profitability. However, proper bookkeeping of informal businesses to measure their profitability and secure more sources of capital from financial institutions was lacking. In addition, Bukaliya and Aleck (2012:63) attributed the low profitability of informal business to financial indiscipline and low levels of training which result in the misuse of funds that otherwise could have been invested in more profitable opportunities to realise business growth

It is thus evident that the basic indicators of informal business growth include the level of employment of the workforce, scale of operation (Alderslade et al. 2006:9; Henley et al. 2006:2; Sparks \& Barnett 2010:1), sales level, profitability, expansion rate and business survival or sustainability (Bukaliya \& Aleck 2012:63; Ligthelm 2013:59; Onwe 2013:62). For the purposes of this study, the basic measures of the growth of informal businesses are sales volume, growth in employment and length of business existence.

\section{Independent variable: The business environment}

The business environment consists of an internal and an external environment (Gupta, Guha \& Krishnaswami 2013:10; Kew \& Stredwick 2017:5). The internal environment includes resources, synergy and distinctive competences of a business. All these together determine the business capability in terms of its strengths and weaknesses existing in different functional areas such as marketing, operations, personnel, financial and technical. In addition, business managers need to monitor the business opportunities and threats that have or are likely to have an influence on their businesses as the internal environment is constantly influenced by the external environment (Gupta et al. 2013:10).

\section{Independent variable: The internal environment}

Gupta et al. (2013:10) concurred with the views of Vrontis and Pavlou (2008:290), arguing that the internal environment is mainly controllable by the business, and therefore, businesses should avoid any problems that are presented within the internal environment that may hamper business growth. Furthermore, an internal audit can examine the business's own resources and supply suggestions as to the business's strengths and weaknesses and affirm that the product development and strategic formation is based upon the internal business capabilities. Oginni and Adesanya (2013:146) highlighted that businesses existed and operated within an environment where there was a complex interplay in terms of activities and networks of relationships between human resources, material resources and other systems. These relationships will define the internal environment of a business.

In a study on factors affecting business success of small and medium enterprises (SMEs) in Thailand, Chittithaworn et al. (2011:182) noted that internal environmental factors including management and know-how, products and services, the way of doing business (business processes) and cooperation between employees, resources and finance were very important in determining the growth of a business. Growth was measured using the following factors: business survival, profit, return on investment, sales growth and the number of employees. In a study on factors limiting the success and growth of small businesses in Tanzania, with the focus on small businesses where the majority were informal in nature, Nkonoki (2010:25) identified three basic internal environmental factors influencing the growth of informal businesses: entrepreneurship, business type and the overall business strategy. These three internal environmental factors all needed to be present for the business to achieve rapid growth. It was concluded that slow growing, no-growth or failing businesses may have some characteristics in one of the three areas (entrepreneurship, business or strategy), but it was only where all three combined effectively that the fastgrowth businesses were found (Nkonoki 2010:25).

A study on the informal sector in Ghana found that the lack of skills and technology affected the level of production of informal businesses (Osei-Boateng \& Ampratwum 2011:6) as these informal businesses employed traditional and manual technologies of production which result in these informal businesses producing little products. The findings are in line with those of Osamwonyi and Tafamel (2010:200) who established that the majority of managers of informal businesses did not have adequate management skills, which adversely affected the survival and growth of these businesses. Other internal environmental factors that limited the scale of operations and production, and thus hampered the growth of informal businesses, were a lack of job security and social protection, which included pension, maternity leave and paid sick leave (Osei-Boateng \& Ampratwum 2011:6). Olawale and Garwe (2010:730) asserted that the business internal environment was largely controllable by the business and included factors such as finance (especially internal finance such as owner's equity contribution and collateral), managerial competence of the owners, location, investment in information technology, cost of production and networking. In addition, Olawale and Garwe (2010:730) noted that the internal business environment was important in influencing business growth. Olawale and Garwe (2010:730) also argued that all businesses required financial resources to start trading and to fund growth, while managerial competences, that is, the sets of knowledge, skills, behaviours and attitudes that contribute to personal effectiveness, were very important to the survival and growth of new businesses. 
From the literature, it can be concluded that the internal environment influences the growth of informal businesses. Growth of informal businesses is dependent on managerial ability to deal with the internal environment. This environment has either a positive or negative influence on business growth. If managers, for instance, are not able to acquire suitable human resource to manage the business properly, the business may not prosper (Nkonoki 2010:25; Olawale \& Garwe 2010:730). In this study, the internal environment challenges that were examined include the staff appropriateness, business knowledge, staff competence, operational planning and strategic planning. As a result, Hypothesis 1 is as follows:

$\mathbf{H}_{\mathbf{1}}$ : There is a significant positive directional relationship between the internal environment and growth of informal businesses in Uganda.

\section{Independent variable: External environment}

The external environment consists of those factors uncontrollable by businesses and includes government regulation, technological changes and the market that has a great influence on the growth of informal businesses (Chittithaworn et al. 2011:182). In addition, Gupta et al. (2013:10) argued that the external environment provided both opportunities and threats to businesses.

A major problem associated with informal activities in the external environment is the lack of regulation. Komollo (2010:2) stated that the majority of informal businesses tend to use public spaces for their activities. This leads to a state of fear for these business owners as to when, rather than if, they would be evicted from their premises. This has led the informal business owners to construct make-shift structures that are poorly serviced, aesthetically unfriendly and environmentally unstable and from which they cannot reap the maximum economic benefits of their trade. In line with Komollo (2010), Osei-Boateng and Ampratwum (2011:6) highlighted that informal businesses tend to escape the regulation of government, and consequently they suffer the neglect of policy makers.

Young, Schaffers and Bruwer (2012:11 322) found that the failure rate of informal businesses was very high and specified that up to $70 \%$ of new businesses failed in their first 2 years of existence. Among the numerous key reasons for the failure were external factors that included economic factors (policies, procedures, inflation rates and interest rates) as well as social factors (crime and infrastructure).

A study on the business environment and growth potential of micro- and small-manufacturing enterprises in Uganda highlighted a number of challenges within the external environment, which included limited access to productive resources and markets as well as high tax rates (Ishengoma \& Kappel 2011:358). Therefore, businesses should scan the external environment for opportunities and threats if they are to survive. These opportunities and constraints are classified into what is generally regarded as the elements of the environment. The elements of the business environment include the economic environment, the political and legal environment and the technological environment (Onodugo \& Ewurum 2013:14). This again offers businesses a number of opportunities as well as threats. The external environment influences the growth of informal businesses through the provision of opportunities in the market where products and services are traded. However, most informal businesses find it difficult to cope with a variety of challenges that are found in the external environment such as competition from formal businesses, and eventually their growth and survival are put at risk. Therefore, depending on the ability of informal businesses to take advantage of opportunities or guard against external challenges (threats), the external environment may positively or negatively influence the growth of informal businesses. Specifically, external opportunities, if effectively utilised, enhance business growth and have a positive influence, while external challenges that cannot be guarded against often lead to business failure (Onodugo \& Ewurum 2013:14; Politis \& Gabrielsson 2006:5). In this study, the external environment challenges that were examined included supplier knowledge, supplier reliability, supplier loyalty, customer loyalty, market share, competition and the legal status. As a result, Hypothesis 2 is as follows:

$\mathbf{H}_{2}$ : There is a significant positive directional relationship between the external environment and growth of informal businesses in Uganda.

Figure 1 shows the theoretical framework used in this study and includes the dependent and independent variables as discussed.

\section{Research methodology and design}

This study adopted a positivistic research design following a quantitative approach. The study population included informal businesses in Kampala district that hosts the majority of informal businesses in Uganda. These informal businesses included those dealing in trade, agriculture and offering services. It is estimated that there is a total of 100000 informal businesses in the Kampala district (Uganda Investment Authority 2011). Business owners of the informal businesses were the target respondents, given that most of these informal businesses are individually owned.

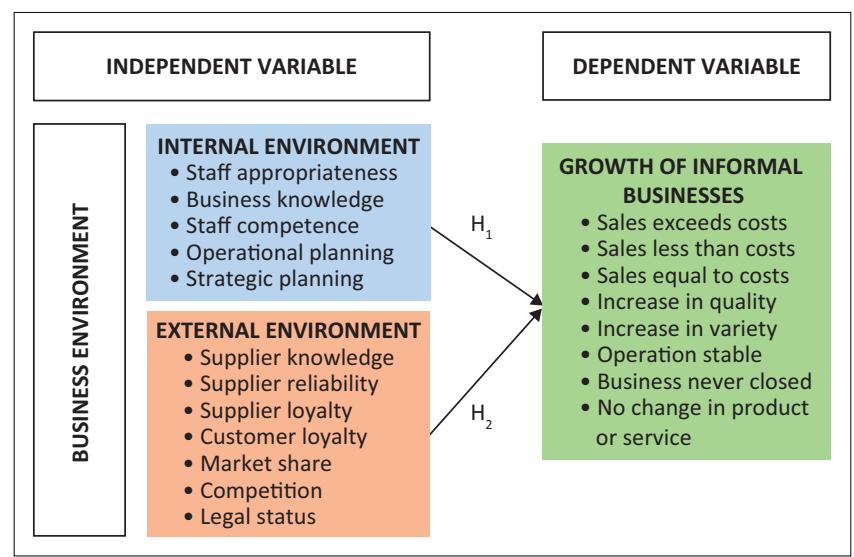

FIGURE 1: Theoretical framework of the relationships between the business environments and growth of informal businesses. 
A sample of 383 respondents was drawn from the population to participate in the study. This was arrived at using the equation for known populations published by the National Educational Association (Amin 2005:256). This sample of informal businesses was selected using probability sampling, namely cluster and systematic sampling. Each of the five divisions, namely Central, Kawempe, Nakawa, Makindye and Rubaga of the Kampala district, formed a stratum and the total sample was evenly distributed among the five divisions (strata). At least 67 informal businesses were selected from each division (stratum) to allow an even distribution across the five divisions (strata). Within each division (stratum), clusters of related businesses were identified and from each cluster, informal businesses were randomly selected for inclusion in the sample. Trained fieldworkers distributed and collected the completed questionnaires.

A self-administered structured questionnaire, consisting of two sections and a cover letter, was used to collect primary data. The questionnaires were delivered and collected from the sample of informal businesses. Questionnaire items were constructed based on the literature. The cover letter explained the purpose of the study as well as the rights (voluntary, anonymity, opt-out option and confidentiality) of the respondents. Section A of the questionnaire collected business profile data such as the respondent's gender and age, the highest educational level, the type and geographic location of the business, the length of time the business had been in existence, the number of employees and the experience the respondent had as a business owner. Section A used closedand open-ended questions. Section B composed of 20 items using an ordinal scale in the form of a five-point Likert-type scale to collect data pertaining to the internal (five items) and external environments (seven items) and growth of the informal businesses (eight items). The five-point scale ranged from 'strongly disagree' (1) to 'strongly agree' (5). The collected data were captured in Microsoft Excel and statistically analysed by using SPSS.

Content validity was attained by conducting a pilot study using convenience sampling after experts in the field of business management assessed the face validity of the questionnaire. The content validity index (CVI) was used to measure the variables of interest or test whether the degree to which the elements of measuring instrument were representative of the construct of interest (Delgado-Rico, Carretero-Dios \& Ruch 2012:450). The necessary changes were made to the questionnaire items after the completion of each validity test. As the CVIs for internal environment (0.80), external environment (0.71) and growth of informal businesses (0.75) were above 0.70 (Tavakol \& Dennick 2011:53; Waltz, Strickland \& Lenz 2005:155), sufficient evidence is provided for content validity.

Exploratory factor analysis (EFA) was used to determine construct validity (Zikmund, Babin, Carr \& Griffin 2013:303) and factors with at least three items having factor loadings of at least 0.4 were considered valid. Cronbach's alpha correlation coefficients were calculated to assess the reliability of the questionnaire where coefficients of 0.70 or greater were regarded as reliable (Drost 2011:106; Hair et al. 2014:123).

The Pearson product moment correlation coefficient was used to determine whether associations existed between the variables (Hauke \& Kossowski 2011:88). Regression analysis was used to test whether significance relationships existed between each of the independent variables (internal and external environments) and the dependent variable (growth of informal businesses).

\section{Ethical consideration}

The anonymity of the respondents was ensured, and ethical clearance was obtained from the organisations involved in the research.

\section{Empirical results}

In the next sections, the sample, measuring instrument and statistical results are discussed.

\section{Sample description}

A total of 383 usable questionnaires were returned. The majority of respondents were women (51.17\%), with $48.83 \%$ men participating in the study. The sample composed of a fairly equal distribution of respondents between the ages of 26 and 35 (29.77\%), 36 and 45 (27.68\%) and 46 years and older (25.84\%). Only $16.71 \%$ of the respondents were in the age group of 16-25 years. Most of the respondents had attained secondary education (38.38\%), a tertiary education (34.47\%) or a primary education $(26.63 \%)$, while two respondents $(0.52 \%)$ had no schooling. Most of the respondents had experience of between 5 and 10 years $(46.74 \%)$ as an owner and less than 5 years $(42.04 \%)$, while only a few respondents $(11.22 \%)$ had more than 10 years' experience as an owner.

The business profile information was also obtained pertaining to the informal businesses that were owned by the respondents. Most of the informal businesses provided services (37.60\%) or sold finished goods (37.34\%), while some of the businesses were involved in manufacturing $(14.62 \%)$ and agriculture (10.44\%).

The informal businesses under investigation were located in five divisions in Uganda, namely the Kawempe division $(21.93 \%)$, the Nakawa division $(21.67 \%)$, the Makindye division (20.89\%), the Rubaga division (19.58\%) and the Central Division (15.93\%). The majority informal businesses included in the sample had been in existence for a period of between 1 and 5 years (43.60\%). The remainder of the informal businesses had been in existence for a period of less than 1 year (26.89\%), followed by those that had been in existence for the period of between 6 and 10 years (19.84\%) and for more than 10 years $(9.67 \%)$. The majority of informal businesses employed less than five employees $(81.98 \%)$, while the remainder employed between 5 and 10 employees (18.02\%). 


\section{Validity and reliability of the measuring instrument}

The measuring instrument was tested for validity and reliability. The independent variable, growth of informal businesses, was measured using eight items, while the two independent variables (internal and external environments) were measured using five and seven items, respectively. The CVI for the three variables ranged between 0.71 and 0.80 , which provided sufficient evidence of content validity as all the CVIs were above 0.7 (Tavakol \& Dennick 2011:53; Waltz et al. 2005:155).

To ensure construct validity, an EFA of a confirmatory nature was performed on each of the variables. Table 1 summarises the various items and factor loadings for the two independent and one dependent variables.

Table 1 shows that only four of the five items developed to measure the internal environment were retained to measure this independent variable, while five of the seven items developed to measure the external environment were retained. Six of the eight items developed to measure growth of informal businesses were retained and used in further analyses. The six items with factor loadings of less than 0.4 were discarded from further analysis. Figure 2 outlines the validated frameworks that were used for empirical testing and shows the items retained in the framework after EFA.

To ensure reliability, Cronbach's alphas were calculated. The Cronbach's alphas for the factors internal environment, external environment and growth of informal businesses were all above 0.7 , which indicated that the factors were internally reliable.

\begin{tabular}{ll} 
TABLE 1: Factor loadings and items of variables. & \\
\hline Items & Factor loadings \\
\hline Internal environment & \\
Staff appropriateness & -0.7617 \\
Business knowledge & -0.8019 \\
Staff competence & -0.7121 \\
Operational planning & -0.8195 \\
Strategic planning & $-0.3146 \dagger$ \\
External environment & \\
Supplier knowledge & -0.8664 \\
Supplier reliability & -0.8227 \\
Supplier loyalty & -0.8868 \\
Customer loyalty & -0.7360 \\
Market share & -0.7277 \\
Competitors & $0.1104 \dagger$ \\
Legal status & $0.3682 \dagger$ \\
Growth of informal businesses & \\
Sales exceed costs & -0.7601 \\
Sales less than costs & -0.8655 \\
Sales equal to costs & -0.8746 \\
Increase in quantity & -0.9973 \\
Increase in variety & -0.8299 \\
Operations stable & $-0.0091 \dagger$ \\
Business never been closed & $-0.2429 \dagger$ \\
No change in products or services & -0.8369 \\
\hline
\end{tabular}

$\dagger$, Factor loadings too low to be retained.

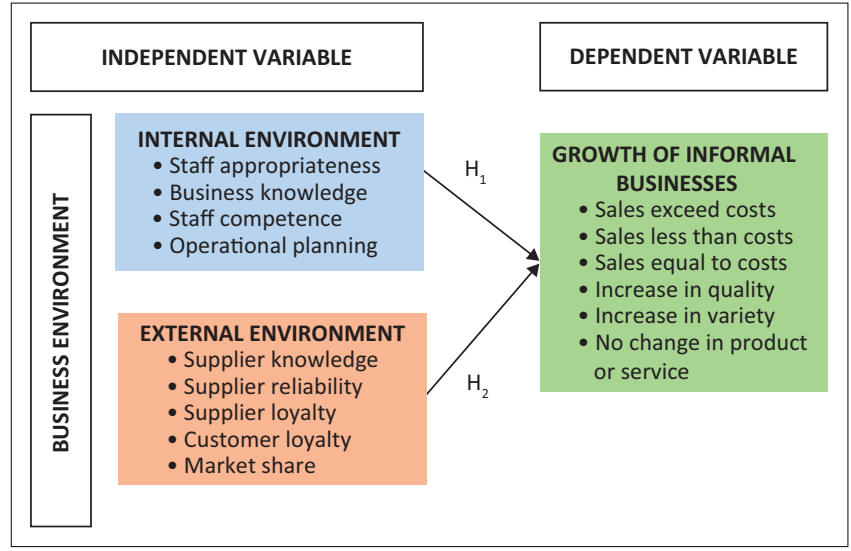

FIGURE 2: Validated framework used for empirical testing of the relationships between the business environments and growth of informal businesses.

\section{Descriptive statistics of the internal environment, external environment and growth of informal businesses}

Descriptive statistics were calculated for the internal and external environments and growth of informal businesses. Regarding the internal environment variable, nearly twothirds $(62.66 \%)$ of the respondents indicated that they agreed that they employed the right people in the business, the employees understood what was expected of them, the employees performed as expected and that the business set targets for less than 1 year. For the external environment variable, most respondents $(81.20 \%)$ agreed that they knew their suppliers, that these suppliers were reliable, and supplies could be purchased on credit from these suppliers, and that the informal business experienced an increase in the number of customers since inception. These results may be explained by the location of the informal businesses that were all located in the city centre and suburbs, providing easy access to various suppliers. The growth of informal business variable showed that most participating informal businesses employed less than five employees, suggesting that they were not growing. Respondents were neutral regarding to the growth of their informal businesses which may indicate that the respondents were unsure about the growth of their informal businesses.

\section{Results of correlation analysis}

Pearson product moment correlation coefficient analysis was used to determine links between the independent and the dependent variables. There was a positive significant moderate correlation between the internal environment and the external environment $(r=0.311 ; p<0.000)$ as well as a positive significant but weak correlation between the internal and growth of the informal businesses $(r=0.118 ; p<0.05)$. However, a weak negative significant correlation existed between the external environment and growth of informal businesses $(r=-0.100 ; p<0.10)$.

\section{Multiple regression analysis and hypotheses testing results}

The assumptions of multiple regression analysis were tested by checking for normality and determined the skewness and 
kurtosis values. These values were acceptable for normality. The variance inflation factors (VIFs) were calculated for the three variables, which ranged from 1.04 to 1.13 , indicating no multi-collinearity. No autocorrelation existed as the DurbinWatson value was 3.05, while the Cook's distance of 0.088 provided support that no significant outliers existed in the data set.

The multiple regression analysis was conducted to determine whether the internal and external environments had a positive directional relationship with growth of informal businesses. The results showed that the internal environment had a statistically significantly relationship with growth of informal businesses, where $F(2.380)=6.811, p<0.01, R^{2}=$ 0.035 . The internal environment had a positive directional relationship ( $b=0.135, p<0.01)$. The external environment, however, presented a negative directional relationship ( $b=-0.162, p<0.01)$ with growth of informal businesses. Therefore, Hypothesis $\mathrm{H}_{1}$ was accepted and $\mathrm{H}_{2}$ was rejected. The $R^{2}$ indicated that the internal and external environments explained $3.46 \%$ of the variation in the data. In addition, the internal environment $(t=3.11)$ exerted a stronger influence on growth of the informal businesses than the external environment $(t=-2.85)$.

\section{Discussion}

The results of this study are in concurrence with the findings of Politis and Gabrielsson (2006:5) and Onodugo and Ewurum (2013:14), who found that the external environment influenced the growth of informal businesses through the provision of opportunities in terms of the market where products and services were sold. However, Politis and Gabrielsson (2006:5) and Onodugo and Ewurum (2013:14) noted that the external environment presented a variety of challenges such as competition from superior formal businesses with which most informal businesses found difficult to compete. These challenges placed additional pressure on the survival and growth of the informal businesses. The directional relationship between the external environment and the growth of the informal businesses is thus negative as shown in this study. This means that the external environmental challenges inhibit the growth of informal businesses.

Olawale and Garwe (2010:730) and Nkonoki (2010:25) found that the internal environment has a significant positive directional relationship on the growth of businesses which is in line with the results of this study. In particular, Olawale and Garwe (2010:730) and Nkonoki (2010:25) highlighted that factors including entrepreneur ability, business characteristics and business strategy were indispensable in shaping the growth of informal businesses. The internal environment thus positively influences the growth of informal businesses.

\section{Conclusions and implications}

The empirical survey reported a significant positive directional relationship between the internal environment and growth of informal businesses and a significant negative directional relationship between the external environment and growth of informal businesses. The results suggest that the external environment presents challenges that impede the growth of informal businesses. However, the internal environment can lead to growth in the informal businesses as employing the right employees while ensuring that all employees understand the business processes, products and services are beneficial to the growth of the informal business. Furthermore, the employees should be informed of the informal business targets. The employees should also be involved in setting the short-term targets, as they were responsible for achieving these targets. Therefore, if targets were attained by informed employees, the informal business might grow in terms of number of loyal customers and profitability.

The results concur with the assertion by Politis and Gabrielsson (2006:5) and Onodugo and Ewurum (2013:14) that the external environment has a significant influence on the growth of informal businesses through the provision of opportunities in terms of the market where they sell their products and services. The external environment presents a variety of challenges such as competition from formal businesses. Most informal businesses find it difficult to compete and cope with the external factors, which may impede the growth of the informal businesses and eventually ruin their survival. Hence, depending on the ability of informal businesses to take advantage of opportunities or guard against external challenges, the external environment has a negative directional relationship with the growth of informal businesses.

It is recommended that informal businesses should strategise to take advantage of the opportunities provided by the external environment while guarding against the threats posed by the same environment. Informal businesses should further maintain good relationships with their suppliers to obtain credit from suppliers and for negotiating more flexible credit terms for credit purchases. Furthermore, informal businesses should take advantage of customer loyalty and ensure that they are fully stocked to maximise sales while retaining their customers. In addition, the informal businesses should focus on differentiated service provision to counteract the efforts of the competitors. This would also assist the informal businesses to increase their number of customers as well as improve sales and profitability, and hence, their business growth.

To conclude, informal businesses in Uganda should scrutinise the internal and external environments for variables that may influence their growth. Once these variables have been identified, appropriate strategies should be developed and implemented to ensure the growth of informal businesses. This study used a validated framework for empirical testing of the relationships between the business environments and growth of informal businesses. This framework can be used in future studies to determine the variables that enhance the growth of informal businesses. 


\section{Acknowledgements}

The authors thank the reviewers of this article for their positive feedback to improve the final quality of the article.

\section{Competing interests}

The authors declare that they have no financial or personal relationships that may have inappropriately influenced them in writing this article.

\section{Authors' contribution}

This article is based on information collected for a PhD study. J.K. was supervisor of the thesis and assisted in the draft article and provided valuable inputs to the final article. F.W.S. was the co-supervisor of the study and she created a draft article from the PhD thesis of G.N. The article was finalised by F.W.S.

\section{References}

Ademola, F. \& Anyankora, M.I., 2012, 'The challenges of improving informal sector activities conditions in Lagos Island, Nigeria', British Journal of Arts and Social Sciences 6(2), 218-232.

Adhikari, D.B., 2012, 'Income generation in informal sector: A case study of the stree vendors of Kathmandu Metropolitan City', Economic Journal of Development Issues 13, 1-14. https://doi.org/10.3126/ejdi.v13i0.7193

Alderslade, J., Talmage, J. \& Freeman, Y., 2006, 'Measuring the informal economy One neighborhood at a time', a discussion paper prepared for the Brookings Institution Metropolitan Policy Program USA, The Brookings Press, CA.

Alemayehu, B.Z. \& Van Vuuren, J., 2017, 'Munificence contingent small business growth model (special emphasis to African SME's context)', Journal of Small Business \& Entrepreneurship 29(4), 251-269. https://doi.org/10.1080/08276331. 2017.1327565

Amin, M.E., 2005, Social science research: Conception, methodology and analysis, Makerere University, Kampala, Uganda.

Barbour, A. \& Llanes, M., 2013, Supporting people to legitimise their informal businesses, Joseph Rowntree Foundation Report, York, England.

Bukaliya, R. \& Aleck, H., 2012, 'Challenges affecting informal business funding in Zimbabwe: Implications for the Zimbabwe Open University', The African Symposium: An online journal of the African Educational Research Network 12(1), 57-72.

Chittithaworn, C., Islam, A., Keawchana, T. \& Yusuf, D.H.M., 2011, 'Factors affecting business success of small \& medium enterprises (SMEs) in Thailand', Asian Socia Science 7(5), 180-190. https://doi.org/10.5539/ass.v7n5p180

De Castro, J.O., Khavul, S. \& Bruton, G.D., 2014, 'Shades of grey: How do informal firms navigate between macro and meso institutional environments?', Strategic Entrepreneurship Journal 8, 75-94. https://doi.org/10.1002/sej.1172

Deen-Swarray, M., Ndiwalana, A. \& Stork, C., 2013, 'Bridging the financial gap and unlocking the potential of informal businesses through mobile money in four East African Countries', CPRsouth8/CPRafrica2013 conference, Mysore, India, 05-07 September, n.p.

Delbiso, T.D., 2013, The role of informal sector employment in poverty alleviation: The case of Hawassa City, Ethiopia, Ethiopia Economics Association, Addis Ababa.

Delgado-Rico, E., Carretero-Dios, H. \& Ruch, W., 2012, 'Content validity evidences in test development: An applied perspective', International Journal of Clinical and Health Psychology 12(3), 449-459.

Donner, J., 2007, 'Customer acquisition among small and informal businesses in urban India: Comparing face to face mediated channels', The Electronic Journal of Information Systems in Developing Countries 32(3), 1-16. https://doi.org/ 10.1002/j.1681-4835.2007.tb00222.x

Drost, E.A., 2011, 'Validity and reliability in social science research', Education Research and Perspectives 38(1), 105-123.

Gupta, P.D., Guha, S. \& Krishnaswami, S.S., 2013, 'Firm growth and its determinants', Journal of Innovation and Entrepreneurship 2(1), 1-14. https://doi.org/10 .1186/2192-5372-2-15

Hair, J.F., Black, W.C., Babin, J.B. \& Anderson, R.E., 2014, Multivariate data analysis, 7th edn., Pearson, Essex.

Hauke, J. \& Kossowski, T., 2011, 'Comparison of values of Pearson's and Spearman's correlation coefficients on the same sets of data', Quaestiones Geographicae 30(2), 87-93. https://doi.org/10.2478/v10117-011-0021-1

Henley, A., Arabsheibani, G.R. \& Carneiro, F.G., 2006, On defining and measuring the informal sector, Discussion Paper No. 2473, World Bank Publications, Washington, DC

Ishengoma, E.K. \& Kappel, R., 2011, 'Business environment and growth potential of micro and small manufacturing enterprises in Uganda', African Development Review 23(3), 352-365. https://doi.org/10.1111/j.1467-8268.2011.00291.x
Kasemiire, C., 2017, 'Why formalising informal sector is a song with no end', Daily Monitor, 07 September, p. 9.

Keter, J., 2012, 'Business competitiveness in the informal sector in rural areas against a background of regulatory frameworks: A study of SMEs in Kesses Division, Uasin Gishu District, Kenya', Journal of Emerging Trends in Educational Research and Policy Studies 3(6), 873-879.

Kew, J. \& Stredwick, J., 2017, Business environment: managing in strategic context, 2nd edn., Chartered Institute of Personnel and Development, London.

Komollo, F.O., 2010, 'Regularization of the informal 'jua kali' activities in Nairobi for sustainable development', 46th ISOCARP Congress, Nairobi, Kenya, 19-23 September, n.p.

Ligthelm, A.A., 2013, 'Confusion about entrepreneurship? Formal versus informal small businesses', Southern African Business Review 17(3), 57-75.

Llanes, M. \& Barbour, A., 2007, Self-employed and micro-entrepreneurs: Informal trading and the journey towards formalization, Community Links, London.

Mbaye, A.A. \& Gueye, F., 2018, 'The competitiveness challenge of the formal sector in Francophone Africa: Understanding the role of the informal sector and the business environment', in I. Adeleye \& M. Esposito (eds.), Africa's competitiveness in the global economy, pp. 25-51, AIB Sub-Saharan Africa (SSA) Series, Palgrave in the global econom
Macmillan, Cham.

Meyer, N., Meyer, D.F. \& Molefe, K.N., 2016, 'Barriers to small informal business development and entrepreneurship: The case of the Emfuleni Region', Polish Journal of Management Studies 13(1), 121-133. https://doi.org/10.17512/ pjms.2016.13.1.12

Mwobobia, F.M., 2012, 'The challenges facing small-scale women entrepreneurs: A case of Kenya', International Journal of Business Administration 3(2), 112-121. https://doi.org/10.5430/ijba.v3n2p112

Nkonoki, E., 2010, What are the factors limiting the success and/or growth of small businesses in Tanzania? - An empirical study on small business growth, International Business, Arcada University of Applied Sciences, Helsinki.

Ogbokor, C.A. \& Ngeendepi, E.J., 2012, Investigating the challenges faced by SMEs in Namibia, University of Science and Technology, Namibia.

Oginni, B.O. \& Adesanya, A.S., 2013, 'Business environmental factors: Implications on the survival and growth of business organisations in the manufacturing sector of Lagos Metropolis', Business and Management Research 2(3), 146-155. https:// doi.org/10.5430/bmr.v2n3p146

Olawale, F. \& Garwe, D., 2010, 'Obstacles to the growth of new SMEs in South Africa: A principal component analysis approach', African Journal of Business Management 4(5), 729-738.

Onodugo, V.A. \& Ewurum, U.J.F., 2013, 'Environmental scanning: An imperative for business survival and growth in Nigeria', Journal of Economics and Sustainable Development 4(7), 12-20.

Onwe, O.J., 2013, 'Role of the informal sector in development of the Nigerian economy: Output and employment approach', Journal of Economics and economy: Output and employmer
Development Studies 1(1), 60-74.

Osamwonyi, I.O. \& Tafamel, A.E., 2010, 'Options for sustaining small and medium scale enterprises in Nigeria: Emphasis on Edo State', African Research Review Journal 4(3b), 192-211. https://doi.org/10.4314/afrrev.v4i3.60249

Osei-Boateng, C. \& Ampratwum, E., 2011, The informal sector in Ghana, FriedrichEbert-Stiftung, Ghana Office.

Politis, D. \& Gabrielsson, J., 2006, Informal investors and value added: What do we know and where do we go?, Paper no. 13, Centre for Innovation, Research and Competence in the Learning Economy, Lund University, Sweden.

Rosemary, M., 2016, 'The social factors that influence growth of women owned businesses in the informal sector in Kenya: A case of women street vendors in Bungoma town, Bungoma District', International Journal of Academic Research in Business and Social Sciences 6(5), 391-412. https://doi.org/10.6007/IJARBSS/v6i5/2156

Sookram, S. \& Watson, P.K., 2008, 'Small-business participation in the informal sector of an emerging economy', Journal of Development Studies 44(10), 1531-1553. https://doi.org/10.1080/00220380802265520

Sparks, D.L. \& Barnett, S.T., 2010, 'The informal sector in Sub-Saharan Africa: Out of the shadows to foster sustainable employment and equity?', International Business \& Economics Research Journal 9(5), 1-12. https://doi.org/10.19030/iber. v9i5.563

Tavakol, M. \& Dennick, R., 2011, 'Making sense of Cronbach's alpha', International Journal of Medical Education 2, 53-55. https://doi.org/10.5116/ijme.4dfb.8dfd

Tshuma, M.C. \& Jari, B., 2013, 'The informal sector as a source of household income: The case of Alice town in the Eastern Cape Province of South Africa', Journal of African Studies and Development 5(8), 250-260.

Uganda Bureau of Statistics (UBOS), 2012, Statistical abstract: Environment demographic, socio-economic, production and macroeconomic statistics, Uganda Government Printers, Kampala, Uganda.

Uganda Investment Authority, 2011, 2010 Baseline survey of small and medium enterprises in Uganda, Draft Final Report, Uganda Investment Authority, Kampala.

Uganda Investment Authority, 2012, Key building blocks for SME support at Ugando Investment Authority, SME Division, Online Survey Report 2012/13, Uganda Investment Authority, Kampala.

Uganda National Household Survey Report, 2010, A bridged report, social economic module, Uganda Bureau of Statistics, Kampala.

UNCTAD, 2007, 'Report of the expert meeting on increasing the participation of developing countries' SMEs in global value chains', Expert meeting on increasing the participation of developing countries' SMEs, Geneva, 18-19 October. 
Van Broembsen, M., 2010, 'Informal business and poverty in South Africa: Re-thinking the paradigm1', Law, Democracy \& Development 14(1), 256-274.

Vrontis, D. \& Pavlou, P., 2008, 'The external environment and its effect on strategic marketing planning: A case study for McDonalds', Journal for International Business and Entrepreneurship Development 3(4), 290-295. https://doi.org/ 10.1504/JIBED.2008.019163

Waltz, C.F., Strickland, O.L. \& Lenz, E.R., 2005, Measurement in nursing and health research, 3rd edn., Springer, New York.
Western Cape Provincial Economic Review and Outlook, 2007, Small, medium and micro enterprises and the informal sector, Western Cape Provincial Treasury, Cape Town.

Young, L., Schaffers, L. \& Bruwer, J.P., 2012, 'South African informal businesses sustainability in the Cape Town Central Business District: The power of internal financial controls', African Journal of Business Management 6(45), 11321-11326. https://doi.org/10.5897/AJBM12.882

Zikmund, W.G., Babin, B.J., Carr, J.C. \& Griffin, M., 2013, Business research methods, 9th edn., South-Western Cengage Learning, Mason, $\mathrm{OH}$ 